\title{
The sound of a mobile phone ringing affects the complex reaction time of its owner
}

Radoslaw Zajdel', Justyna Zajdel², Anna Zwolińska³, Janusz Śmigielski², Piotr Beling11, Tomasz Cegliński, Dariusz Nowak ${ }^{3}$

1Department of Medical Informatics and Statistics, Medical Univeristy of Lodz, Poland 2Department of Medical Law, Inter-Department of Human Sciences,

Medical University of Lodz, Poland

${ }^{3}$ Chair of Experimental and Clinical Physiology, Medical University of Lodz, Poland

Submitted: 23 May 2011

Accepted: 5 December 2011

Arch Med Sci 2012; 8, 5: 892-898

DOI: 10.5114 /aoms.2012.28891

Copyright (c) 2012 Termedia \& Banach

\section{Abstract}

Introduction: Mobile phone conversation decreases the ability to concentrate and impairs the attention necessary to perform complex activities, such as driving a car. Does the ringing sound of a mobile phone affect the driver's ability to perform complex sensory-motor activities? We compared a subject's reaction time while performing a test either with a mobile phone ringing or without. Material and methods: The examination was performed on a PC-based reaction time self-constructed system Reactor. The study group consisted of 42 healthy students. The protocol included instruction, control without phone and a proper session with subject's mobile phone ringing. The terms of the study were standardised.

Results: There were significant differences $(p<0.001)$ in reaction time in control (597 ms), mobile (633 ms) and instruction session (673 ms). The differences in female subpopulation were also significant $(p<0.01)$. Women revealed the longest reaction time in instruction session $(707 \mathrm{~ms})$, were significantly quicker in mobile (657 ms, $p<0.01)$ and in control session $(612 \mathrm{~ms}, p<0.001)$. In men, the significant difference was recorded only between instruction (622 ms) and control session (573 ms, $p<0.01$ ). The other differences were not significant $(p>0.08)$. Men proofed to complete significantly quicker than women in instruction $(p<0.01)$ and in mobile session $(p<0.05)$. Differences amongst the genders in control session was not significant $(p>0.05)$.

Conclusions: The results obtained proofed the ringing of a phone exerts a significant influence on complex reaction time and quality of performed task.

Key words: mobile phone, complex senso-motoric activities, reaction time.

\section{Introduction}

Everyday experience, as well as the results of numerous reports, indicates that mobile phone conversation decreases the ability to concentrate and impairs the attention necessary to perform complex activities, such as driving a car [1-5]. Driving is a complex sensory-motor process, requiring simultaneous shifting of attention, engagement of short and long term memory, and the ability to filter stimuli with consequent evaluation of their importance and to perform appropriate complex reactions. It is also a psychological process with a wide spectrum of dependencies, including driving speed, road conditions and distance [6]. We decided to reduce the variables in this complex equation to obtain more explicit results and conclusions. It has been shown that the presence of additional signals and noise phenomena disturbing the flow
Corresponding author: Radoslaw Zajdel MD Department of Medical Informatics and Statistics Medical University of Lodz 1 Hallera sq.

90-647 Lodz, Poland

Phone: +48 426393244

E-mail: zajdel@toya.net.pl 
in the two-way sensory-motor information channel has a negative effect on safety and ability to drive a car $[4,5]$. Cavanagh et al. revealed, using the multiple object-tracking paradigm, that a person can track only 3-5 items simultaneously [7]. The results of these studies justify the bans on the use of communication devices while driving, which are implemented in a large group of countries. It is worth emphasizing that the disruption of drivers' attention concerns not only the use of hand-held phones but also hands-free ones $[4,5]$.

Analysis of the available literature does not provide an answer to the question whether the ringing sound of a mobile phone affects the driver's ability to perform complex sensory-motor activities such as driving. In the present study, an attempt has been made to answer this question by evaluating the effect of the phone ringing on the time of the driver's complex reaction.

\section{Material and methods}

The study compared a subject's reaction time while performing a test either with a mobile phone ringing or without. The experimental group comprised 25 women and 17 men aged 19-22 years. They all were students of the Medical University of Lodz, Poland.

Students qualified for the study were not under the influence of any chemical substances; they did not drink tea, coffee or other stimulating drinks for at least $12 \mathrm{~h}$ before the examination and slept well the night prior to the experiment. All tests were held during the same part of the day, between $8.30 \mathrm{am}$ and $11.00 \mathrm{am}$.

The investigations were carried out in normalised conditions such as the use of the same computer, the same room, identical light, as well as analogous background sound. The computer system consisted of a regular personal computer equipped with a 21-inch CRT display monitor. A bespoke application designed to examine simple and complex reaction time ('Reactor') was installed on the computer [8]. The study subjects responded to stimuli by pressing buttons in two computer-coupled manipulators, with one button for each hand. A testing session comprised 72 stimuli, both visual and acoustic. All reactions had an alternative character: they were associated with the necessity of choosing a response, i.e. pressing the right or left manipulator depending on the type of stimulus. The experiment was designed in this way to investigate the complex reaction time of participants. This is an effective method and less demanding for the patient than neuropsychological tests. It enables the studies to be performed outside of the laboratory, in "normal" daily circumstances [9].

Reaction time in the present study is the time needed for perception, evaluation of a stimulus and a response. A simple reaction is referred to as a response of the participant to a single stimulus, in which there is no element of choice between stimulus modalities. Complex, or alternative, reactions concern situations in which each person examined has to discriminate the type of the stimulus and its corresponding reaction within "the time of the reaction choice", being an element of the reaction time [8]. The complex reaction time has been confirmed to be significantly longer than the simple reaction time. The other studies use reaction time for example to evaluate reading acquisition or to decode a word from the articulatory speech component [10]. In the present study, only complex reactions have been dealt with because of their involvement in the process of driving $[4,5,7]$.

Students prior to the tests filled in a simple questionnaire in which they answered the qualifying questions and gave their cell phone numbers. The study included three sessions: instruction, in which students learned how to use the programme; control, in which the telephone did not ring; and the proper session, during which the authors of the study called the students on their cell phone, and the students did not know who was calling. The first call was made exactly at the $60^{\text {th }} \mathrm{s}$ of the test; the phone was ringing for $20 \mathrm{~s}$; next the authors waited for $10 \mathrm{~s}$ and called for the second time. The subjects were instructed not to answer the phone and to continue the examination.

During all three sessions the student's mobile phone was lying before computer-coupled manipulators and the subjects did not know who was calling. Two cases when the students' phones were ringing unintentionally were excluded from the study. The reaction time was measured in milliseconds and rounded up to the nearest whole number.

\section{Statistical analysis}

The results were subjected to statistical analysis, including some multidimensional tests. Normal distribution was assessed with the Shapiro-Wilk test. As the distribution of the characteristic tested in the male population was not within the norm, a nonparametric multidimensional analysis, Friedman's ANOVA test, was performed, and the bidimensional analysis of correlations of the parameters studied was checked by means of the nonparametric Wilcoxon test. The statistical significance was set at $p<0.05$.

\section{Results}

The longest reaction time (673 ms) was observed in the instruction session and the mobile phone session (633 ms), the shortest one in the control session (597 ms). The analysis demonstrated a statistically significant correlation between the reaction time 
of the group studied and the type of test, i.e. a significant difference in the reaction time was detected in the control session as compared to the instruction session and the mobile phone session. There was also a statistically significant difference between the instruction session and the mobile phone session. Detailed data are shown in Table I.
Figure 1 illustrates the distribution of reaction times in the study group.

Similar results occurred in the group of women; the longest reaction time was observed in the instruction session (707 ms) and the mobile phone session (657 ms); the control session appeared to have the shortest reaction time (612 ms).

Table I. Analysis of the reaction time according to test type

\begin{tabular}{|lccc|}
\hline Reaction time [ms] & $\begin{array}{c}\text { Control session } \\
\text { (group 0) }\end{array}$ & $\begin{array}{c}\text { Instruction session } \\
\text { (group 1) }\end{array}$ & $\begin{array}{c}\text { Mobile phone session } \\
\text { (group 2) }\end{array}$ \\
\hline Number of subjects & 42 & 42 & 42 \\
\hline Minimum & 431.62 & 468.54 & 420.02 \\
\hline Maximum & 857.67 & 939.84 & 1003.20 \\
\hline Median & 598.26 & 673.88 & 629.63 \\
\hline Arithmetic mean & 596.52 & 672.56 & 632.71 \\
\hline Standard deviation & 90.95 & 108.91 & 109.95 \\
\hline Asymmetry coefficient & 0.69 & 0.21 & 1.12 \\
\hline Statistical analysis & \multicolumn{4}{c}{$\begin{array}{c}\text { Friedman's ANOVA test } F=26.62, p<0.001 \\
\end{array}$} \\
\end{tabular}

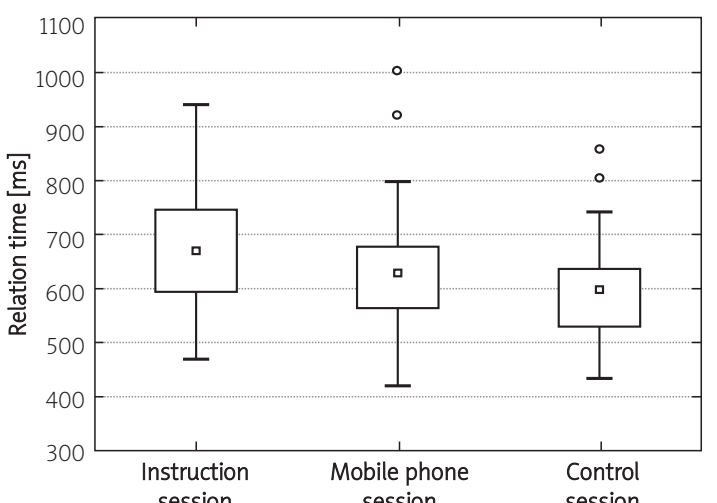
session

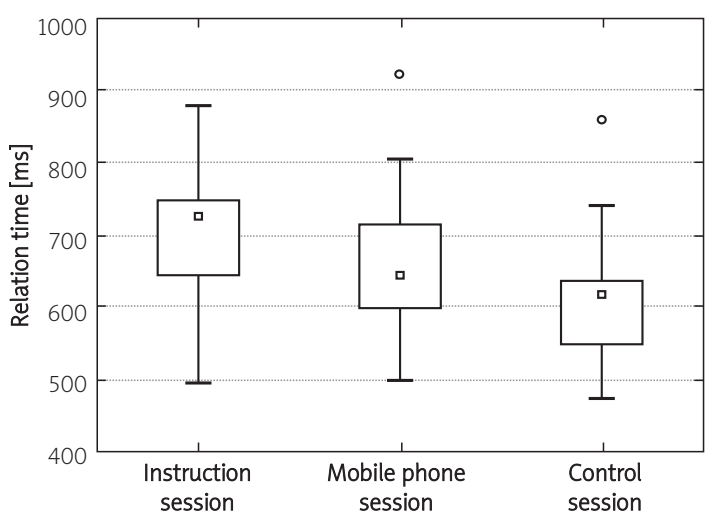

$\square$ Median $\square 25-75 \% \quad$ IRange of non-outliers $\bigcirc$ Outliers

Figure 1. Distribution of reaction times in the study

Figure 2. Distribution of reaction times in women group

Table II. Analysis of the reaction time in women according to test type

\begin{tabular}{|lccc|}
\hline Reaction time [ms] & $\begin{array}{c}\text { Control session } \\
\text { (group 0) }\end{array}$ & $\begin{array}{c}\text { Instruction session } \\
\text { (group 1) }\end{array}$ & $\begin{array}{c}\text { Mobile phone session } \\
\text { (group 2) }\end{array}$ \\
\hline Number of subjects & 25 & 25 & 25 \\
\hline Minimum & 474.39 & 495.76 & 498.71 \\
\hline Maximum & 857.67 & 939.84 & 1003.20 \\
\hline Median & 614.78 & 723.95 & 643.98 \\
\hline Arithmetic mean & 612.26 & 707.10 & 657.39 \\
\hline Standard deviation & 86.93 & 94.93 & 89.01 \\
\hline Asymmetry coefficient & 0.87 & -0.41 & 0.98 \\
\hline Statistical analysis & \multicolumn{4}{c}{$\begin{array}{c}\text { Friedman's ANOVA test } F=20.72, p<0.001 \\
\end{array}$} \\
\end{tabular}


Table III. Analysis of the reaction time in men according to test type

\begin{tabular}{|c|c|c|c|}
\hline Reaction time [ms] & $\begin{array}{l}\text { Control session } \\
\text { (group 0) }\end{array}$ & $\begin{array}{l}\text { Instruction session } \\
\quad \text { (group 1) }\end{array}$ & $\begin{array}{l}\text { Mobile phone session } \\
\text { (group 2) }\end{array}$ \\
\hline Number of subjects & 17 & 17 & 17 \\
\hline Minimum & 431.62 & 468.54 & 420.02 \\
\hline Maximum & 803.75 & 939.84 & 1003.20 \\
\hline Median & 552.88 & 612.75 & 591.03 \\
\hline Arithmetic mean & 573.37 & 621.76 & 596.43 \\
\hline Standard deviation & 94.37 & 110.77 & 129.41 \\
\hline Asymmetry coefficient & 0.78 & 1.41 & 1.90 \\
\hline Statistical analysis & \multicolumn{3}{|c|}{$\begin{array}{l}\text { Friedman's ANOVA test } F=7.88, p<0.05 \\
\text { t } 0.1 z=3.15, p<0.01 ; \text { Wilcoxon test } 0.2 z=1.11, p>0.05 \\
\text { Wilcoxon test } 1.2 z=1.73, p>0.05(p=0.08)\end{array}$} \\
\hline
\end{tabular}

The analysis revealed a significant correlation between the reaction time of the group studied and the type of the test, i.e. there was a statistically significant difference in the reaction time in the control session in comparison to the instruction and mobile phone session. The female subjects were characterized by a statistically significant difference between the instruction session and the mobile phone session, which was in accordance with the results for the entire population. More detailed data are included in Table II. Figure 2 illustrates the distribution of reaction times in women.

The longest reaction time in the male group was seen in the instruction session (622 ms), and the mobile phone session $(596 \mathrm{~ms})$, while the shortest one was found in the control session (573 ms). The analysis showed a statistically significant correlation between the reaction time in the group studied and the type of the test, which differed from the results for the female subjects, where all the differences between the sessions appeared to be significant. In the male group, a statistically significant difference occurred only between the control session and the instruction session. In the remaining cases, no significant difference was noted. Detailed data are presented in Table III. Figure 3 illustrates the results obtained in the group of men.

\section{Discussion}

There are numerous original works available in the literature that analyse the effect of using cell phones on sensory-motor abilities such as driving performance. These studies have been carried out in laboratory conditions [11], using models resembling a car cockpit [2, 3, 12, 13], as well as under the conditions of natural road traffic [14]. It was found that phone conversation impairs sensorymotor activities. As a consequence, all authors agree that the implementation of bans on using cell phones while driving is justified. This impairment is complex and indicates the involvement

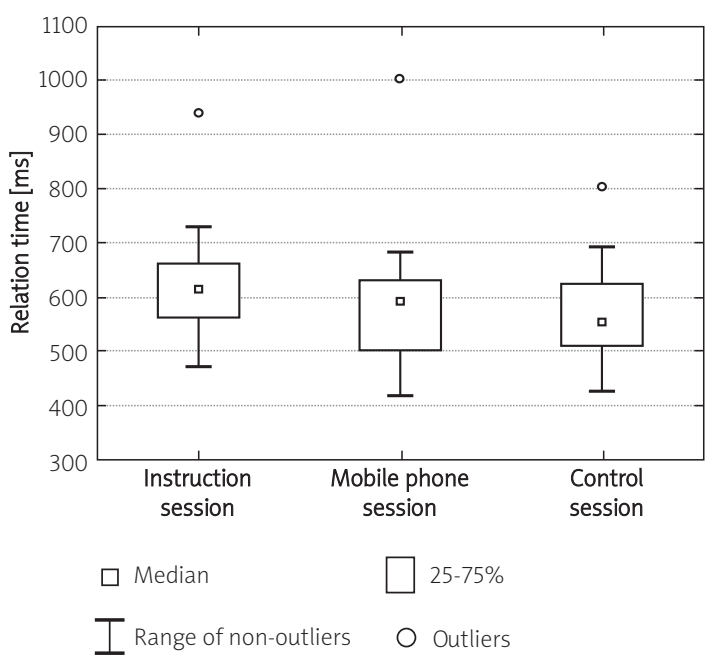

Figure 3. Distribution of reaction times in men

of the central nervous system [1], decreasing visual ability [11] or speed of performing movements necessary for braking $[12,13]$. The investigators believe that the drivers' distraction refers not only to the use of hand-held phones but also hands-free sets [14]; and it is not associated with the sex of subjects examined. The authors of the present study have not found any reports in the available literature which analyse the impact of the sound of a phone ringing on a subject's ability to drive, an example of a complex activity. Experience shows that the fact of hearing the sound of a phone ringing, recognized by the driver as his own phone, induces some kind of tension and frequently makes the driver reach for the phone, which may result from anticipation of a conversation or an interest in checking who is calling. The results of our study confirm this observation and reveal that the ringing of a phone exerts a significant influence on complex reaction time. The subsequent analysis compared the reaction times according to subjects' sex within 
a session. In previous studies, the authors found significant differences in the reaction time: men were found to respond more quickly than women [8]. The analysis of parameters in the present study was carried out using the nonparametric MannWhitney $U$ test. Men were revealed to have a significantly shorter reaction time in the instruction session $(z=2.90, p<0.01)$ and in the mobile phone session $(z=2.38, p<0.05)$, while no statistically significant difference was found in the control session $(z=1.38$, $p>0.05)$. The detailed results are presented in Table IV. Figure 4 illustrates the distribution of reaction times according to the sex of the group studied.

Analysis of the data in subgroups concerning the subjects' sex demonstrated that the reaction time in women was significantly longer in the mobile phone session than in the control one. A longer reaction time in the instruction session is associated with

Table IV. Analysis of the reaction time according to the gender of the group studied

\begin{tabular}{|c|c|c|c|c|c|c|}
\hline \multirow[t]{2}{*}{ Reaction time [ms] } & \multicolumn{2}{|c|}{ Control session } & \multicolumn{2}{|c|}{ Instruction session } & \multicolumn{2}{|c|}{ Mobile phone session } \\
\hline & Women & Men & Women & Men & Women & Men \\
\hline Number of subjects & 25 & 17 & 25 & 17 & 25 & 17 \\
\hline Minimum & 474.39 & 431.62 & 495.76 & 468.54 & 498.71 & 420.02 \\
\hline Maximum & 857.67 & 803.75 & 880.64 & 939.84 & 920.61 & 1003.20 \\
\hline Median & 614.78 & 552.88 & 723.98 & 612.75 & 643.98 & 591.03 \\
\hline Arithmetic mean & 612.26 & 573.37 & 707.10 & 621.76 & 657.39 & 596.43 \\
\hline Standard deviation & 86.93 & 94.37 & 94.93 & 110.77 & 89.01 & 129.41 \\
\hline Asymmetry coefficient & 0.87 & 0.78 & -0.41 & 1.41 & 0.98 & 1.90 \\
\hline Statistical analysis & Test $Z_{\text {Man }}$ & $\frac{a}{2}=1.38$ & Test $Z_{\text {Man }}$ & $=2.90$ & Test $Z_{\text {Mann }}$ & $\begin{array}{l}\text { eya }=2.38, \\
05\end{array}$ \\
\hline
\end{tabular}
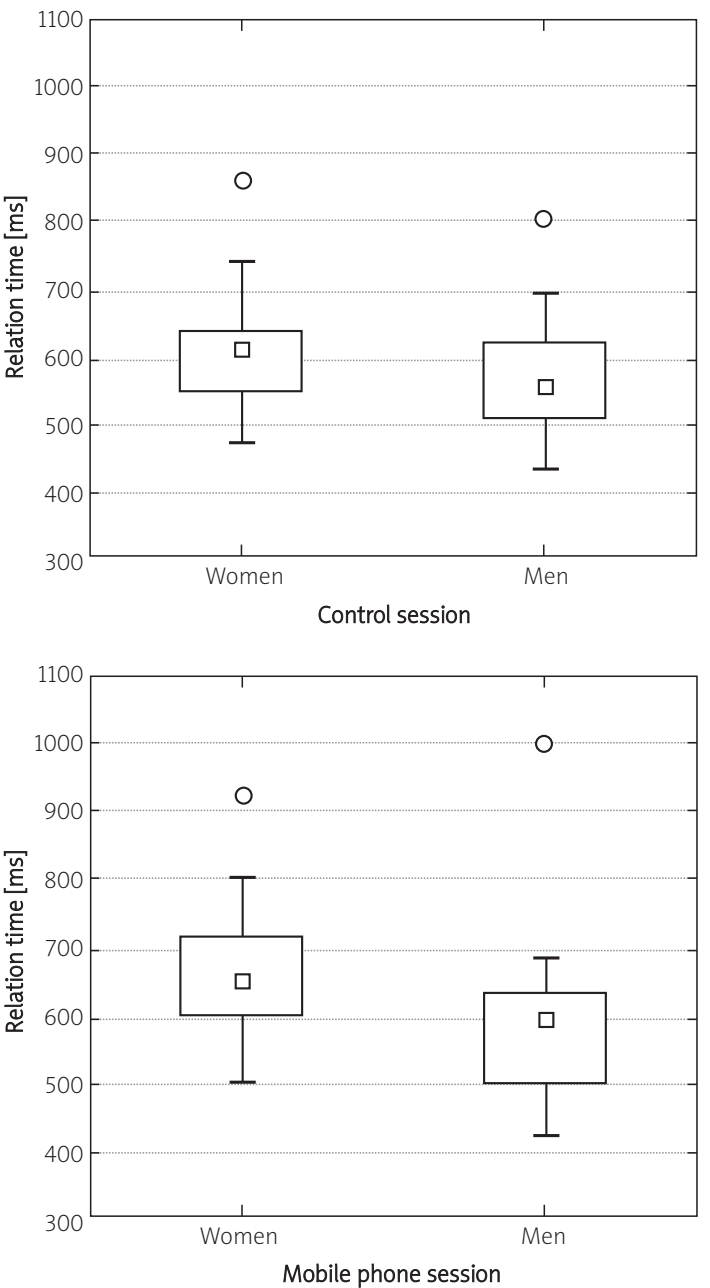

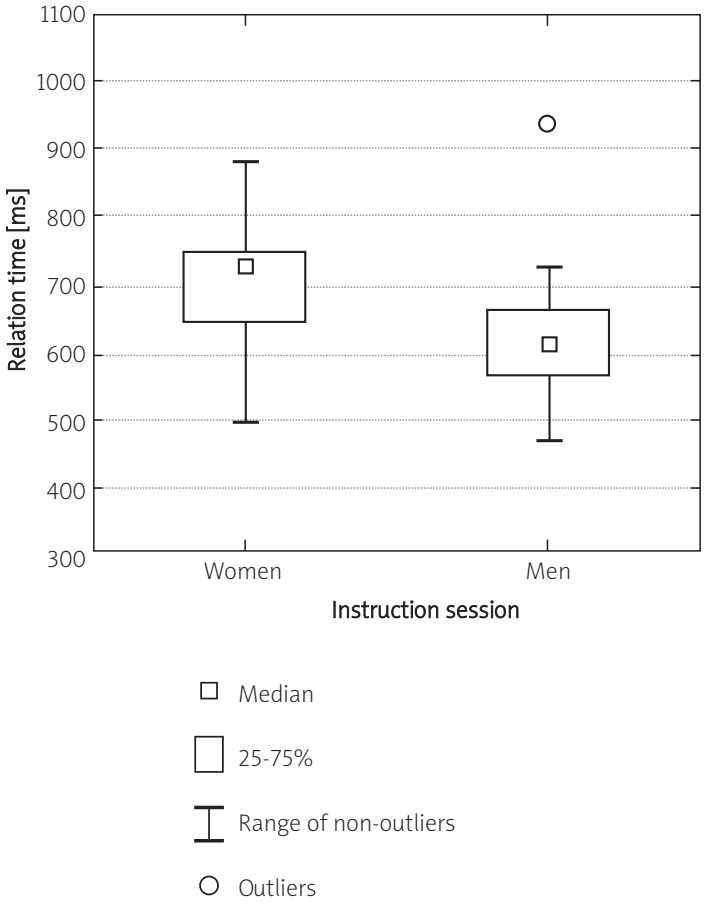

Figure 4. Analysis of reaction time according to the sex of the group studied 
the fact that the subjects examined get used to the device. This time is always longer in both sexes. The authors of the present study have confirmed this finding in their earlier work [8].

However, there was no significant difference observed in the male subpopulation between the mobile phone session and the other ones. Interesting relationships have been found by comparing the same sessions between sexes. Women had a significantly longer reaction time in the mobile phone session and the instruction session as compared to men, but this difference was not present in the control session.

This result is consistent with the outcome of our previous research, in which women were proven to have a statistically significantly longer reaction time than men while performing the same task [8]. There are no reports in the literature that would explain this finding. There are some studies analysing a delaying effect of the cell phone conversation on the drivers' reactions; however, the impact of the phone ringing alone has not been studied so far. These investigations imply that the effect of the cell phone conversation does not depend on gender [12-14]. On the basis of our results and the previous research, it is likely that women have a longer reaction time than men; however, this finding should be verified by proper testing with the use of the same diagnostic tool in identical conditions.

In our previous work [8], an attempt was made to determine the cause of the obtained results, which might have been associated with the phase of the menstrual cycle and its effect on female reaction time. The significance of the menstrual cycle phase has also been emphasised by other authors $[15,16]$. Moreover, some researchers who did not deal with the direct impact of the phone conversation demonstrated that women's reaction time is generally significantly longer than that of men [ 17 , 18]. Such a situation might be explained by a more pronounced phenomenon of lateralization in the men's brain. This observation has been reported earlier by numerous authors [17-21].

Additionally, according to other studies, the physiological interpretation of the phenomenon of a longer reaction time in females than males is based on the influence of oestrogen on brain function. McEwan et al. state that oestrogens that predominate in the follicular phase of the cycle affect the efficiency of psychophysical functions through the regulation of synaptogenesis in the hippocampal CA1 region [22]. The reported effect of oestrogens concerns the acceleration of the $N$-methyl-D-aspartate (NMDA) receptor, an ionotropic glutamate receptor which is the main regulator of the calcium channels in the brain, having an influence on synapse activity [23]. It is worth mentioning that progesterone inhibits NMDA, which is believed to contribute to a decrease in psychophysical abilities [22]. Further- more, the same studies show that oestrogens also affect the activity of the brain stem, serotoninergic conduction in the mesencephalon, and cholinergic conduction in the subcortical nuclei. Other studies based on animal models report that oestrogens stimulate the development of neurons in different areas of the brain [24]. Orłowska-Majdak et al. emphasizes that oestrogens positively influence hippocampal plasticity via the stimulation of synapse development, and accelerate brain development via shortening the time of neuronal myelination, which is of great importance even in the first days of hormonal activity [25].

The outcome of the present study indicates that the ringing of a cell phone belonging to a person performing a complex psychomotor activity exerts a significant effect on the quality of the performed task. Cell phones are omnipresent nowadays so drivers should use hands-free equipment while driving (at least) to improve road traffic safety. Although further research carried out in more realistic driving conditions is required for accurate determination of the influence of a ringing phone on a driver, these study results suggest that this influence may be significant.

\section{Acknowledgments}

Radoslaw Zajdel and Justyna Zajdel contributed equally to this work.

\section{References}

1. Kunar MA, Carter R, Cohen M, Horowitz TS. Telephone conversation impairs sustained visual attention via a central bottleneck. Psychon Bull Rev 2008; 15: 1135-40.

2. Strayer DL, Drews FA, Johnston WA. Cell phone-induced failures of visual attention during simulated driving. J Exp Psychol Appl 2003; 9: 23-32.

3. Strayer DL, Drews FA. Cell-phone-induced driver distraction. Curr Dir Psychol Sci 2007; 16: 128-31.

4. Strayer DL, Drews FA, Crouch DJ. A comparison of the cell phone driver and the drunk driver. Hum Factors 2006; 48: 381-91.

5. Strayer DL, Johnston WA. Driven to distraction: dual-task studies of simulated driving and conversing on a cellular telephone. Psychol Sci 2001; 12: 462-6.

6. Törnros J. Effect of driving speed on reaction time during motorway driving. Accid Anal Prev 1995; 27: 435-42.

7. Cavanagh P, Alvarez GA. Tracking multiple targets with multifocal attention. Trends Cogn Sci 2005; 9: 349-54.

8. Zajdel R, Nowak D. Simple and complex reaction time measurement: a preliminary evaluation of new approach and diagnostic tool. Comput Biol Med 2007; 37: 1724-30.

9. Ajtay Z, Kellényi L, Hejjel L, et al. Simple and choice reaction times are prolonged following extracorporeal circulation: a potential method for the assessment of acute neurocognitive deficit. Med Sci Monit 2009; 15: CR470-6.

10. De Luca M, Zeri F, Spinelli D, Zoccolotti P. The acquisition of reading fluency in an orthographically transparent language (Italian): an eye movement longitudinal study. Med Sci Monit 2010; 16: SC1-7. 
11. Barkana Y, Zadok D, Morad Y, Avni I. Visual field attention is reduced by concomitant hands-free conversation on a cellular telephone. Am J Ophthalmol 2004; 138: 347-53.

12. Irwin M, Fitzgerald C, Berg WP. Effect of the intensity of wireless telephone conversations on reaction time in a braking response. Percept Mot Skills 2000; 90: 1130-4.

13. Consiglio W, Driscoll P, Witte M, Berg WP. Effect of cellular telephone conversations and other potential interference on reaction time in a braking response. Accid Anal Prev 2003; 35: 495-500.

14. McCartt AT, Hellinga LA, Bratiman KA. Cell phones and driving: review of research. Traffic Inj Prev 2006; 7: 89-106.

15. Resnick A, Perry W, Parry B, Mostofi N, Udell C. Neuropsychological performance across the menstrual cycle in women with and without premenstrual dysphoric disorder. Psychiatry Res 1998; 77: 147-58.

16. Man MS, MacMillan I, Scott J, Young AH. Mood, neuropsychological function and cognitions in premenstrual dysphoric disorder. Psychol Med 1999; 29: 727-33.

17. Misra N, Mahajan KK, Maini BK. Comparative study of visual and auditory reaction time of hands and feet in males and females. Indian J Physiol Pharmacol 1985; 29: 213-8.

18. Dawe S, Corballis MC. The influence of gender, handedness and head-turn on auditory asymmetries. Neuropsychologia 1986; 24: 857-62.

19. Stalans L, Wedding D. Superiority of the left hemisphere in the recognition of emotional faces. Int J Neurosci 1985; 25: 219-23.

20. Davidson H, Cave KR, Sellner D. Differences in visual attention and task interference between males and females reflect differences in brain laterality. Neuropsychologia 2000; 38: 508-19.

21. Watson NV, Kimura D. Right-hand superiority for throwing but not for intercepting. Neuropsychologia 1989; 27: 1399-414.

22. McEwen BS, Alves SE, Bulloch K, Weiland NG. Ovarian steroids and the brain: implications for cognition and aging. Neurology 1997; 48 (5 Suppl. 7): S8-15.

23. Kossut M. Wstęp do neuroplastyczności. Neurol Neurochir Pol 2002; 36 (Suppl. 1): 11-21.

24. Tanapat P, Hastings NB, Reeves AJ, Gould E. Estrogen stimulates a transient increase in the number of new neurons in the dentate gyrus of the adult female rat. J Neurosci 1999; 19: 5792-801

25. Orłowska-Majdak M, Kołodziejski P, Traczyk WZ. Sex difference in rabbit eyelid conditioning. Acta Neurobiol Exp 2001; 61: 135-40. 